\title{
Prototipe Robot Avoider sebagai Mesin Penggerak Robot Medical Assistant
}

\author{
Bayu Fandidarma*1, Yuda Ragil Praditya ${ }^{2}$, Yan Gusti Kurniawan ${ }^{3}$ \\ 1,2,3 Universitas PGRI Madiun, Indonesia, Fakultas Teknik, Prodi Teknik Elektro \\ e-mail: *1bayuf@unipma.ac.id, ${ }^{2}$ yudaragilpraditya@gmail.com, \\ ${ }^{3}$ kurniawangusti90@gmail.com
}

\begin{abstract}
Abstrak
Permasalahan yang diangkat pada penelitian ini adalah membangun prototipe mesin penggerak Robot Medical Assistant yang memiliki fungsi Obstacle Avoidance dengan gerak otonom. Penelitian yang sudah dilaksanakan sebelumnya masih menggunakan joystik untuk menggerakkan robot atau dengan kata lain robot masih secara manual disetir manusia. Karena sangat tidak reliable dan terlalu bergantung pada manusia, maka metode setir manual ini perlu ditingkatkan performanya dengan pengaplikasian metode otonom pada robot. Maka dalam penelitian ini disuguhkan suatu metode yang lebih baik supaya robot dapat bergerak secara otonom dan memiliki fungsi Obstacle Avoidance supaya robot dapat menghindari halangan dengan baik. Jadi user menentukan titik tujuan dimana saja dan tugasnya apa lalu menekan tombol 'START' ketika robot siap berangkat. Pengujian dilakukan dengan memberikan perintah untuk robot bergerak dari satu lokasi ke lokasi lainnya dengan dipasang beberapa halangan pada jalur yang tersedia. Dari pengujian ini mendapatkan hasil bahwa robot lumayan berhasil menghindari hambatan dan pergi ke tujuan dengan rerata kesalahan pengukuran sensor sebesar $1.25 \%$.
\end{abstract}

Kata kunci-Mobile robot, Obstacle avoidance, Robot medical assistant, Sistem otonom

\begin{abstract}
The problem raised in this study is to build a prototype of the Robot Medical Assistant driving machine which has the Obstacle Avoidance function with autonomous motion. Research that has been carried out before is still using a joystick to move the robot, or in other words, the robot is still manually driven by a human. Because it is very unreliable and too dependent on humans, this manual steering method needs to be improved by applying autonomous methods to robots. So in this study a better method is presented so that the robot can move autonomously and have an Obstacle Avoidance function so that the robot can avoid obstacles well. So the user determines the destination and what the task is then pressing the 'START' button when the robot is ready to go. The test is carried out by giving commands for the robot to move from one location to another with several obstacles installed on the available paths. From this test, the results show that the robot is quite successful in avoiding obstacles and going to its destination with an average sensor measurement error of $1.25 \%$.
\end{abstract}

Keywords-Autonomous system, Mobile robot, Obstacle avoidance, Robot medical assistant 


\section{PENDAHULUAN}

Mewabahnya pandemi Covid-19 belakangan ini sangat berpengaruh pada berbagai aspek kehidupan manusia. Berbagai macam sektor merasakan dampak yang diantaranya sektor ekonomi, pangan, militer, wisata, transportasi, perbankan, pendidikan, budaya dan sektor kesehatan yang jelas terdampak paling besar. Tenaga kesehatan (nakes) yang terdiri atas dokter, perawat, mahasiswa kedokteran, penyedia alat kesehatan dan peran penting lainnya, telah bekerja dengan sepenuh hati, tenaga, jiwa dan raga. Mereka adalah benteng terpenting untuk membendung dan mengatasi pandemi Covid-19 ini. Telah banyak juga yang tumbang bahkan sampai gugur dalam 'peperangan' ini.

Perlu dilakukan hal-hal untuk memudahkan tugas dan kerja nakes. Salah satu diantaranya adalah dibangunlah Robot Medical Assistant. Robot ini tidak menggantikan nakes tapi meminimalisir tenaga kesehatan untuk masuk dan bertemu dengan pasien. Selain mengurangi frekuensi interaksi perawat dengan pasien, Robot ini juga berpotensi untuk meningkatkan kenyamanan pasien. Kemudian juga dapat mengurangi penggunaan Alat Pelindung Diri (APD) tenaga medis. Robot ini mampu memberikan pelayanan kepada pasien yang sedang diisolasi seperti mengantar makanan, pakaian, maupun obat-obatan. Perlunya sentuhan hati dan interaksi langsung dibutuhkan juga sesekali untuk mendukung psikologi dari pasien Covid-19 sendiri.

Robot Medical Assistant terbagi dalam beberapa bagian utama yaitu (1) Mesin Penggerak, (2) Antarmuka Manusia-Mesin-Manusia dan (3) Konstruksi Tubuh Penyusun Robot. (1) Mesin Penggerak memiliki tugas untuk menggerakkan robot berpindah dari satu lokasi ke lokasi yang lain dengan lancar, aman dan tanpa benturan. Untuk kenyamanan dan kemudahan pengoperasian, Mesin Penggerak dibangun berdasarkan pada model Robot Avoider. Model Robot Avoider ini adalah robot yang bergerak menggunakan roda dan memiliki fungsi khusus yaitu dapat mendeteksi halangan atau hambatan di depannya lalu berusaha untuk menghindarinya. (2) Antarmuka Manusia-Mesin-Manusia memiliki tugas untuk menyambung dan memudahkan komunikasi antara tenaga kesehatan (nakes), pasien dan robot itu sendiri. Tatanan dasarnya berupa layar monitor yang menampilkan segala macam data dan informasi yang dapat dibaca, didengar dan dipahami oleh pasien maupun nakes dengan mudah dan simpel. Sehingga komunikasi antara pasien dan nakes dapat berjalan dengan lancar. (3) Konstruksi Tubuh Penyusun Robot adalah desain tubuh yang diperlukan robot supaya robot dapat berfungsi dengan benar dan ergonomis dan dapat dipakai pada banyak situasi dan kondisi. Dimensi dan bentuk tubuh robot sangatlah penting untuk didesain sedemikian rupa supaya penggunanya tidak canggung dalam menggunakan robot tersebut dan robot dapat menghemat pemakaian bahan bangun tetapi tetap kuat dan kokoh. Dalam penelitian kali ini difokuskan pada perakitan prototipe (1) Mesin Penggerak yang memiliki fungsi Obstacle Avoidance (menghindari hambatan atau halangan) untuk Robot Medical Assistant.

Untuk menghindari halangan, sudah ada beberapa penelitian sebelumnya yang membahas hal tersebut. Terdapat penelitian yang didasarkan pada kesulitan yang dialami pasien saat terbaring di rumah sakit dan dia merancang suatu robot yang dapat membantunya beraktifitas tanpa menunggu perawat/dokter datang [1]. Lalu penelitian selanjutnya yang membahas kendaraan berjalur-terarah yang dapat kembali lagi ke jalurnya jika menemui hambatan [2]. Menghindari hambatan juga dibahas pada penelitian yang lain pada pembentukan formasi beberapa agen supaya tidak mengalami 
benturan antar agennya [3]. Dalam perencanaan jalur robot dengan hambatan statis, perlu perhitungan yang pasti untuk menghindari hambatan sesuai dengan jalur yang telah direncanakan [4]. Untuk mobil robot yang memiliki heading, penelitian ini fokus pada seberapa optimal robot menghindari hambatan dinamis supaya jalur yang ditempuh adalah minimal [5].

Artikel ini disusun berdasarkan urutan sebagai berikut. Metode Penelitian dipresentasikan pada bab II. Bab III berisikan Hasil dan Pembahasan dan Bab IV dirumuskan Kesimpulan untuk mengetahui hasil akhirnya.

\section{METODE PENELITIAN}

Pada bagian ini, metode penelitian dijabarkan berdasarkan dasar teori dan fungsi yang diinginkan untuk merumuskan hasil penelitian dan selanjutnya dianalisa untuk diambil kesimpulannya.

\subsection{Konsep Obstacle Avoidance}

Mobile robot adalah robot yang ciri konstruksinya menggunakan roda atau kaki sebagai aktuatornya untuk menggerakan keseluruhan badan robot, sehingga robot tersebut dapat berpindah dari satu tempat ke tempat lain dengan sistem navigasi yang berasal dari sensor. Roda sebagai daya penggerak sudah sangat populer digunakan oleh banyak orang karena mudah dan tidak perlu memikirkan dan melakukan perhitungan dari sisi keseimbangan dimana itu sangat rumit. Kinerja dari mobile robot bergantung pada komponen-komponen dasar seperti hardware dari robot (body, motor, sensor, dan lain-lain), kondisi lingkungan tempat robot bekerja, dan programming .

Robot obstacle avoidance bertujuan untuk menghindari tabrakan dengan penghalang. Disebut obstacle avoidance karena robot ini hanya akan bergerak menghindari objek yang bergerak mendekat di depannya tanpa kembali ke jalurnya.

\subsection{Sistem Robot Avoider}

Kontrol proporsional bekerja dengan cara mengalikan nilai gain proportional dengan error. Kelebihan yang dimiliki oleh kontrol proporsional adalah bentuknya yang sederhana dan kecepatan responnya, dimana dalam penelitian ini sangat dibutuhkan kecepatan respon yang baik. Kontrol digunakan untuk mengatur keluaran berupa PWM. Pulse Width Modulation (PWM) adalah teknik yang umumnya digunakan untuk mengontrol daya ke perangkat listrik, dirancang praktis dengan modern switch daya elektronik. PWM digunakan untuk mendapatkan hasil analog dengan cara digital atau PWM merupakan cara digital tingkat pengkodean sinyal analog.

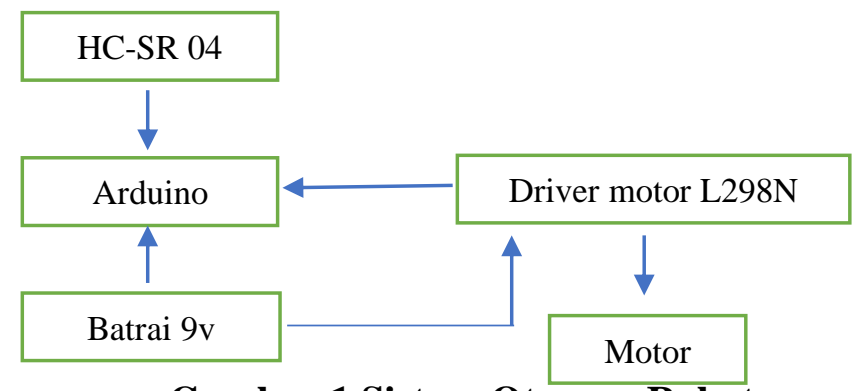

Gambar 1 Sistem Otonom Robot 


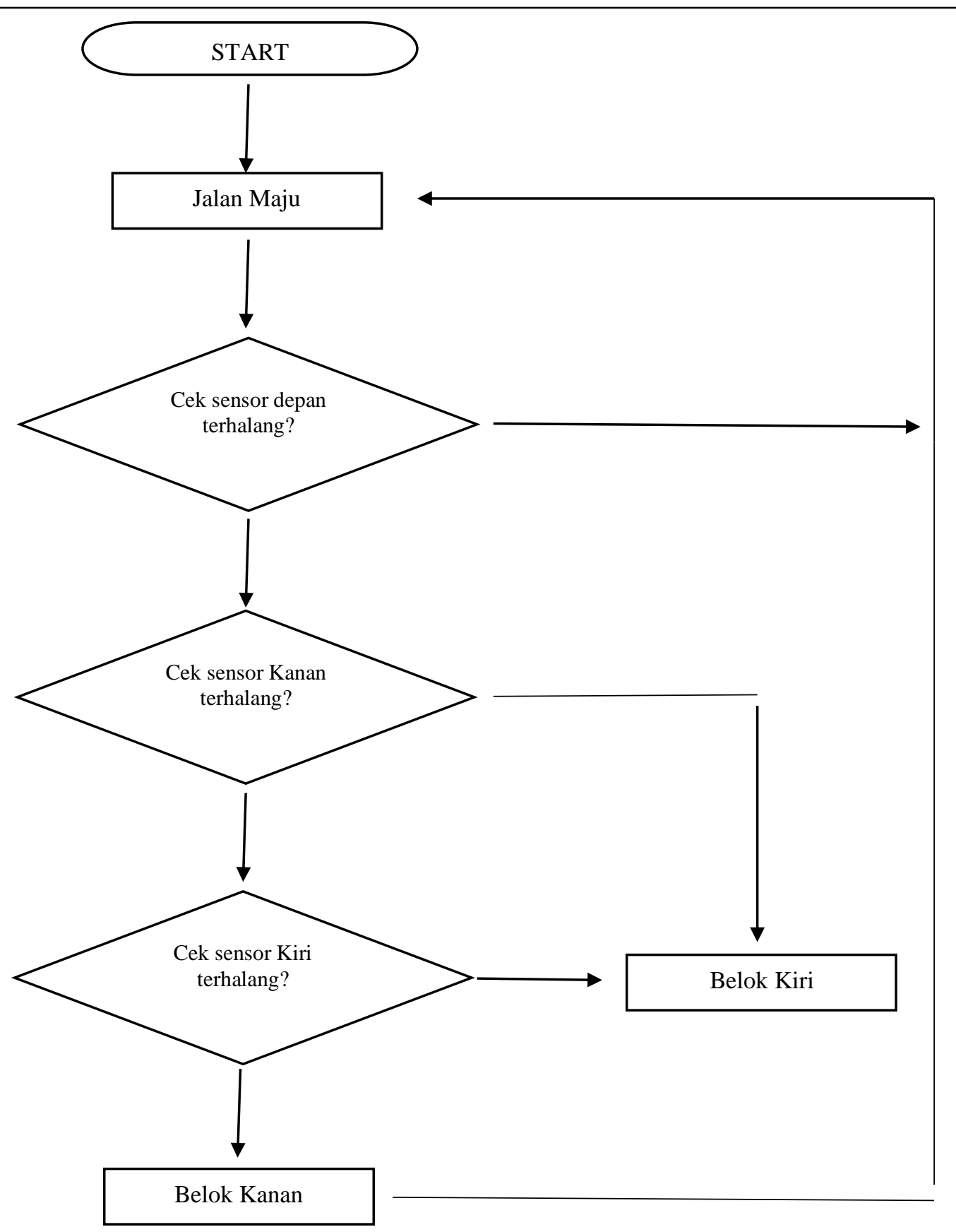

Gambar 2 Flowchart Sistem Otonom Robot

\subsection{Komponen Robot Avoider}

Sensor yang digunakan dalam penilitian ini yaitu sensor jarak menggunakan HC SR05. Sensor HC SR05 hanya digunakan di bagian depan. Untuk mikrokontroler pada robot digunakan Arduinno Uno. Arduino UNO adalah papan mikrokontroler berdasarkan ATmega328P. Arduino ini berisi semua yang diperlukan untuk mendukung mikrokontroler, untuk mengaktifkan cukup menghubungkannya ke komputer dengan kabel USB dengan adaptor AC-DC atau baterai. Kemudahan penggunaan Arduino Uno merupakan alasan dipilihnya komponen tersebut. Driver motor pada penelitian ini 
menggunakan L298N. Dan untuk menggarakan sensor ultrasonic mengguanakn Servo SG90.

\subsection{Pengujian Prototipe Robot Avoider}

Robot Avoider diuji untuk menunjukkan bahwa fungsi avoidance-nya tidak terpenuhi, sebagian terpenuhi atau terpenuhi. Pengujian dilakukan dengan memberikan perintah pada robot untuk bergerak lurus dari titik $\mathrm{P}$ ke titik Q dengan jarak tertentu dan terpasang beberapa halangan pada jalur yang tersedia. Kemampuan robot untuk menghindari halangan sangat penting dalam penelitian kali ini.

\section{HASIL DAN PEMBAHASAN}

Dari data yang telah didapat menunjukkan keakuratan pengukuran dari sensor ultrasonik PING. Dari 10 percobaan pengukuran jarak hanya terdapat 3 kesalahan pengukuran. Masing-masing pengukuran memiliki kesalahan $1.25 \%$. Selain itu data tersebut juga menunujukkan bahwa semakin jauh jarak obyek pengukuran maka akurasi pengukurannya cenderung menurun. Kemudian dilakukan pengujiian sensor ultrasonik PING terhadap media halangan.

Data-data hasil pengukuran jarak sensor ultrasonik digunakan untuk proses kinerja robot. Data jarak dari sensor ultrasonik, akan digunakan untuk acuan bagi robot dalam menentukan arah belokan, sehingga robot tidak dapat menabrak saat terdapat halangan yang menghambat laju robot tersebut. Dari data pada tabel diketahui bahwa sensor ultrasonik PING sangat efektif bila dinding penghalangnya adalah benda padat dan keras.

Kendala yang di dapat ketika membuat robot ini di antaranya masalah pemograman ketika semua komponen sudah di rangkai, terpasang dengan rapi sesuai panduan dan mulai me-upload pemograman mengalami kegagalan, program gagal diupload bahkan ketika di verifikasi di software arduino IDE gagal ternyata penyebabnya adalah library belom dimasukkan ternyata kita harus menambahkan library yang di butuhkan dan benar saja ketika sudah di tambahkan robot bisa berjalan sesuai arahan. Namun ada lagi sebuah kendala ketika semua sudah beres ternyata baterai mengalami kendala baterai yang di pasang tidak dapat bertahan lama yang membuah robot berjalan lambat bahkan cenderung susah jalan di situ kami mencoba menggunakan baterai vapor (rokok elektrik) dengan tegangan 3,70 V dan arus sebesar $2600 \mathrm{mAH}$ yang diseri, disitu berjalan sesuai dengan rencana.

\section{KESIMPULAN}

Kesimpulan yang dapat dirangkum dari pengujian yang telah dilakukan dijabarkan sebagai berikut:

1. Robot mobile penghindar halangan dapat diaplikasikan untuk berbagai macam keperluan, antara lain untuk keperluan navigasi, mata-mata/pengintai dan robot ini juga dapat digunakan sebagai penjelajah daerah yang sulit dijangkau oleh manusia.

2. Mobile robot adalah robot yang ciri konstruksinya menggunakan roda atau kaki sebagai aktuatornya untuk menggerakan keseluruhan badan robot, sehingga robot tersebut dapat berpindah dari satu tempat ke tempat lain dengan sistem navigasi 
yang berasal dari sensor.

3. Robot avoider bertujuan untuk menghindari tabrakan dengan penghalang. Robot ini hanya akan bergerak menghindari objek yang bergerak mendekat di depannya tanpa kembali ke jalurnya.

4. Robot advoider yang dirancang sangan terpengaruh oleh kapasitas baterai. Oleh karena itu agar robot berjalan dengan baik maka baterai yang digunakan harus dalam keadaan prima.

5. Pengembangan yang bisa di lakukan di robot ini mungkin bisa di tambahi ketika jarak yang di tentukan sudah tercapai robot tidak langsung berhenti namun roda berhenti secara perlahan tidak langsung seketika.

\section{DAFTAR PUSTAKA}

[1] S. Mahajan, and C.M. Vidhyapathi, "Design of a Medical Assistant Robot," in $2^{\text {nd }}$ IEEE International Conference On Recent Trends in Electronics Information \& Communication Technology (RTEICT), India, 2017.

[2] M. Septyan, and T. Agustinah, "Trajectory tracking automated guided vehicle using fuzzy controller," in $1^{\text {st }}$ IEEE International Conference of Artificial Intelligence and Information Technology (ICAIIT), Yogyakarta, 2019.

[3] B. Fandidarma, A. Jazidie, and R.E.A. Kadier, "Forming formation of particle swarm using Artificial Neural Network Self Organizing Map (ANN-SOM) with 2leveled strategy," in $1^{\text {st }}$ IEEE International Conference of Artificial Intelligence and Information Technology (ICAIIT), Yogyakarta, 2019.

[4] N.S. Utami, A. Jazidie, and R.E.A. Kadier, "Path planning for differential drive mobile robot to avoid static obstacles collision using modified crossover Genetic Algorithm," in $3^{\text {rd }}$ IEEE International Seminar on Intelligent Technology and Its Applications (ISITIA), Surabaya, 2019.

[5] A.D. Pambudi, T. Agustinah, and R.E.A. Kadier, "Reinforcement point and fuzzy input design of Fuzzy Q-learning for mobile robot navigation system," in $1^{\text {st }}$ IEEE International Conference of Artificial Intelligence and Information Technology (ICAIIT), Yogyakarta, 2019. 